Current Eye Research

ISSN: 0271-3683 (Print) 1460-2202 (Online) Journal homepage: https://www.tandfonline.com/loi/icey20

\title{
Yellow Filter Effect on Melatonin Secretion in the Eye: Role in IOP Regulation
}

\section{Victoria Eugenia Lledó, Hanan Awad Alkozi \& Jesús Pintor}

To cite this article: Victoria Eugenia Lledó, Hanan Awad Alkozi \& Jesús Pintor (2019): Yellow Filter Effect on Melatonin Secretion in the Eye: Role in IOP Regulation, Current Eye Research, DOI: 10.1080/02713683.2019.1570276

To link to this article: https://doi.org/10.1080/02713683.2019.1570276

Accepted author version posted online: 14 Jan 2019. Published online: 24 Jan 2019.

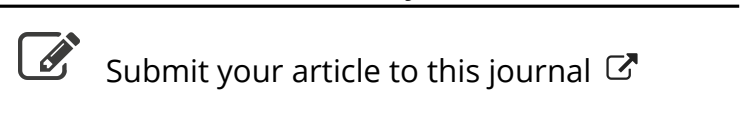

山 Article views: 18

View Crossmark data ¿ 


\title{
Yellow Filter Effect on Melatonin Secretion in the Eye: Role in IOP Regulation
}

\author{
Victoria Eugenia Lledó, Hanan Awad Alkozi, and Jesús Pintor \\ Department of Biochemistry and Molecular Biology, Faculty of Optics and Optometry, University Complutense of Madrid, Madrid, Spain
}

\begin{abstract}
Purpose: Melatonin is a neurohormone mainly synthesized in the pineal gland; however, it is also present in the aqueous humor. One of melatonins' functions in the eye is the regulation of intraocular pressure (IOP). Melatonin is known to be sensitive to light. Recently, the photopigment which controls melatonin synthesis, melanopsin, was found in the crystalline lens. Therefore, light conditions are an interesting possible way of regulating melatonin levels in the aqueous humor. The current study used yellow filters, since melanopsin is activated by short wavelength (blue light).

Methods: New Zealand white rabbits were used, divided in two groups, one under controlled $12 \mathrm{~h}$ light/ dark cycles, while the rest had their cages encased with a yellow filter ( $\lambda$ 465-480). IOP measurements were taken every week at the same time before they were anesthetized for aqueous humor extraction. Results: Keeping the rabbits under the yellow filter resulted in a decrease in IOP up to $43.8 \pm 7.8 \%$ after 3 weeks. This effect was reversed after the topical application of selective and nonselective melatonin receptors antagonists, 4PPDOT and luzindole. Also, blocking melanopsin by its antagonist AA92593 under white light condition decreased IOP. Finally, melatonin levels were found significantly higher in the aqueous humor of rabbits developed under yellow filter compared to controls $(37.4 \pm 4.2$ and $15.3 \pm 3.1 \mathrm{ng} / \mathrm{ml}$, respectively).

Conclusion: Yellow filters modulate melatonin levels in the aqueous humor due to deactivating melanopsin activity. This effect leads to a decrease in IOP mediated by melatonin receptors.
\end{abstract}

\section{ARTICLE HISTORY}

Received 19 October 2018

Revised 10 December 2018

Accepted 7 January 2019

\section{KEYWORDS}

Yellow filter; intraocular pressure; melatonin; melanopsin

\section{Introduction}

Melatonin ( $\mathrm{N}$-acetyl-5-methoxytryptamine) is a molecule first discovered and described in the pineal gland. ${ }^{1}$ It was classically considered to be exclusively produced by this structure until years later when melatonin synthesizing enzymes were found in several organs and structures. ${ }^{2}$ Among the huge number of organs and cells producing melatonin, the eye was one of the first organs discovered to synthesize melatonin, first starting from the retina. ${ }^{2}$ Afterward, the attention was attracted to several ocular structures and melatonin now is known to be synthesized in the iris, ciliary body, ${ }^{3}$ crystalline lens, ${ }^{4,5}$ and the lacrimal gland. ${ }^{6}$

In the eye, melatonin plays numerous functions. It has the ability to accelerate corneal wound healing, ${ }^{7}$ it serves as an antioxidant in the eye, and it protects the eye against oxidative stress due to aging or diseases. ${ }^{8-10}$ Moreover, melatonin lowers intraocular pressure (IOP) and participates in the physiology of the aqueous humor, as well as the pathophysiology of glaucoma. ${ }^{11,12}$

Glaucoma is a multifactorial disease which results in a progressive irreversible optic neuropathy and peripheral visual field loss. ${ }^{13}$ It is the second leading cause of vision $\operatorname{loss}^{14}$ and it is developed as a consequence of several risk factors, the only controllable one being IOP. ${ }^{15}$ Glaucoma can be controlled through different drugs aiming to lower IOP. Nevertheless, apart from the commercially available compounds, more substances such as melatonin and its analogs rise as a possible therapeutic agent to lower IOP and control glaucoma. ${ }^{12}$

Melatonin synthesis is controlled by light-darkness cycles and this is specially relevant in the eye since it is the window of the body to the outside. Several years ago, a photo pigment named melanopsin was described in a small subclass of the retinal ganglion cells. These studies showed that it participates in a nonimage forming pathway since it was active and functional in blind subjects and, moreover, in enucleated mice. ${ }^{16-}$ ${ }^{18}$ This photo pigment is responsible for photo-entrainment, and its activation occurs by means of short wavelength light $(470-480 \mathrm{~nm})$ leading to melatonin suppression. ${ }^{19}$

Evidences during the last three decades have indicated that illumination, received by the eye, has an influence in many human physiological and behavioral aspects. ${ }^{20,21}$ For instance, light constricts the pupil, increases heart rate, body temperature, and suppresses melatonin synthesis. ${ }^{22,23}$ Based on these changes in the physiology carried out by light, several therapeutic applications have been developed. ${ }^{24}$ For example, light has been shown to have antidepressant properties, specially for the treatment of seasonal effective disorder, ${ }^{25,26}$ also, a proper timed light exposure has been developed as a therapy for circadian rhythm sleep disorders and circadian disruption due to jet lag, and finally light has been used for depression treatment. ${ }^{27,28}$ On the other hand, short wavelength light presents some serious harm to the

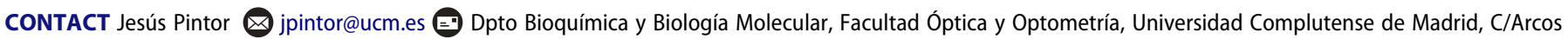
de Jalón, 118, Madrid E-28037, Spain.

Color versions of one or more of the figures in the article can be found online at www.tandfonline.com/icey.

(c) 2019 Taylor \& Francis Group, LLC 
eye, since it could lead to retinal cells damage. ${ }^{29,30}$ All these studies and discoveries highlight the importance of light and, consequently, melanopsin physiological role.

Recently, melanopsin has been described in the crystalline lens epithelium of humans. This study has shown that epithelial crystalline lens cells responded to light by modifying melatonin levels. An increment in melatonin was observed after hours of incubation in darkness, while under light conditions, the synthesis of this substance was abolished. This effect was confirmed to be regulated by melanopsin present in the lens. ${ }^{31}$ Together with the fact that melatonin is present in the aqueous humor, due to its synthesis in the ciliary body, we believe that melatonin is also coming from neighbor tissues in contact with the aqueous humor such as the crystalline lens.

In the current work, we show how melatonin present in the aqueous humor can be modulated by means of yellow filters in New Zealand white rabbits and how the presence of this substance can modify IOP.

\section{Material and methods}

\section{Animals}

Male New Zealand white rabbits, weighing an average of $2.5 \pm 0.5 \mathrm{~kg}$, were used for this study. The animals were kept in individual cages with free access to food and water. The control and pharmacological groups were kept under controlled $12 \mathrm{~h}$ day-night cycles, while a different group was kept in cages enveloped with a yellow filter, though receiving $12 \mathrm{~h}$ day-night cycles. This study adhered to the ARVO Statement for the Use of Animals in Opthalmic and Vision Research, and also all animal care and experimental procedures were carried out in accordance with the European Communities Council Directive (86/609/EEC).

\section{Experimental procedures}

The effect of the yellow filter (465-480) as well as the pharmacological compounds which were tested measuring IOP were carried out using a TonoVet contact tonometer supplied by Tiolat Oy (Helsinki, Finland). All the measurements were performed at the same time of the day, $10 \mathrm{am}$, in order to minimize IOP variations. The TonoVet takes five consecutive IOP measurements and calculate the mean of the value. At any given time, IOP is measured three times and the values obtained were transformed into mean \pm s.e.m. For the experiments using the yellow filter, IOP was measured once a week during 1 month before taking them out of the filter to study the possible change during the following month. For pharmacological assays, two measurements were taken at $30 \mathrm{~min}$ interval before any substance was added. IOP was measured at different intervals of time depending on the experiment, and the substances were applied topically $(20 \mu \mathrm{l})$ in a bilateral way.

For the filter group, $20 \mu \mathrm{l}$ cocktail of luzindole (nonspecific antagonist for melatonin receptors) and 4PPDOT (4-phenyl2-propionamidotetralin, MT2 specific antagonist), both provided from Tocris, Bristol, UK, were administered as eye drops at final concentration of $100 \mu \mathrm{M}$. Experiments were done after 3 weeks in yellow filter-covered cages. IOP measurements were taken after 10,30, 45, 60, 90, $120 \mathrm{~min}$ of instillation.

For the control group, $20 \mu \mathrm{l}$ of AA92593 (melanopsin antagonist, prepared in PEG-400, DMSO, SML0865, Sigma, St. Louis, Mo, USA) was used at a final concentration of $100 \mu \mathrm{M}$. IOP measurements were done at $20 \mathrm{~min}, 40 \mathrm{~min}$, $1,2,3,4,5$, and $6 \mathrm{~h}$ after applying the antagonist.

For the aqueous humor collection, rabbits were anesthetized with a subcutaneous injection of a mixture of ketamine $(7.5 \mathrm{mg} /$ $\mathrm{kg}$, Imalgene 1000, Merial, Barcelona, Spain) and Domitor (0.25 mg/mg, DOMTOR ${ }^{\circ}$, Orion Pharma, Espoo, Finland). Aqueous humor $(100 \mu \mathrm{l})$ was extracted with a syringe connected with a 30-ga needle in the sacro-corneal limbus. Samples were stored in $-20^{\circ} \mathrm{C}$ until the time of the analysis.

Samples of the aqueous humor were processed for HPLC (High Performance Liquid Chromatography) analysis using the protocol described elsewhere. ${ }^{32}$ Briefly, samples were submitted to a $98^{\circ} \mathrm{C}$ dry bath for $2 \mathrm{~min}$ before they were transferred to ice during $10 \mathrm{~min}$, finally, the samples were centrifuged to pellet proteins at $13,000 \mathrm{~g}$ for $10 \mathrm{~min}$ at $4^{\circ} \mathrm{C}$ before the injection. In brief, the column was a Kromaphase C18 column $5.0 \mathrm{~mm}(25 \mathrm{~cm}$ in length, $0.4 \mathrm{~cm}$ inner diameter) (Scharlau, Madrid, Spain). The system was equilibrated overnight with $40 \%$ methanol and $60 \% \mathrm{H}_{2} \mathrm{O}$. Measurements were performed at a flow rate of $0.8 \mathrm{ml} / \mathrm{min}$ fixing the detector at a wavelength of $244 \mathrm{~nm}$. The chromatographic system for all the determinations consisted of a 1515 Isocratic HPLC pump, a 2487 dual absorbance detector, and a Rheodyne injector, all managed by the software Breeze from Waters (Milford, MA). Quantification melatonin was performed by comparing the samples with the corresponding external standard provided by Sigma.

\section{Statistical analysis}

Data represent the mean \pm s.e.m of separate indicated number of experiments for each case, and statistical significance was calculated by ANOVA or Student $t$-test when necessary. All the plots were obtained by GraphPad Prism (GraphPad Software Inc., San Diego, CA).

\section{Results}

\section{Effect of yellow filter on IOP}

Recently, the presence of melanopsin and its effect on ATP release have been demonstrates in New Zealand with rabbits. ${ }^{33}$ Rabbits maintained under the yellow filter presented a significant reduction of IOP, this reduction was most appreciated after 3 weeks under the yellow filter. IOP decreased up to $43.8 \pm 7.8 \%\left({ }^{* * *} p<0.0001, n=6\right)$ compared to the control animals (Figure 1A). This effect was completely reversed $30 \mathrm{~min}$ after the topical application of both the selective and nonselective melatonin receptor antagonists, 4PPDOT and luzindole, respectively (Figure 1B). This is a clear indication of the involvement of melatonin receptors in the hypotensive effect observed by the use of this filter. When the rabbits were placed under white light/darkness cycles, it resulted in a gradual recovery of the IOP reaching values similar to the control ones after 4 weeks (Figure $1 \mathrm{~A} ;{ }^{* * *} p<0.0001, n=6$ ). 


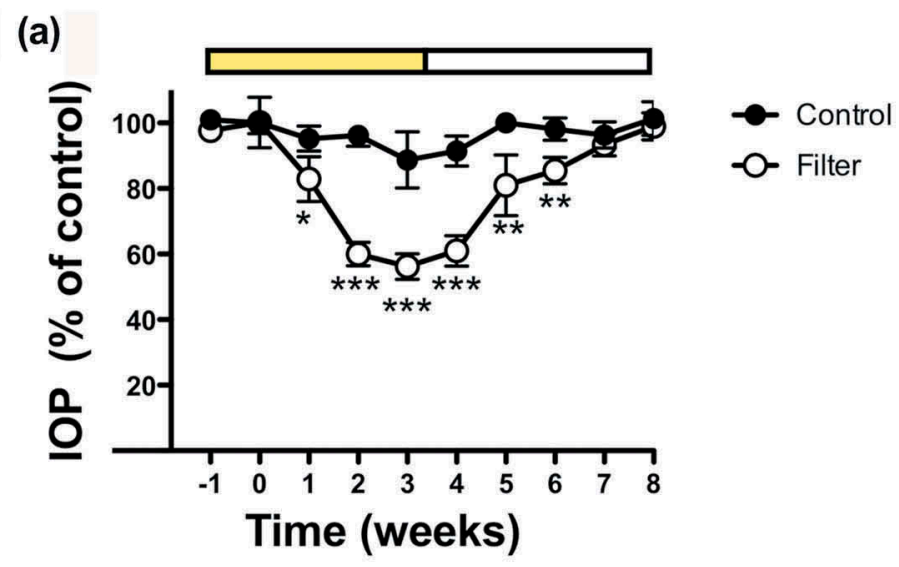

(b)

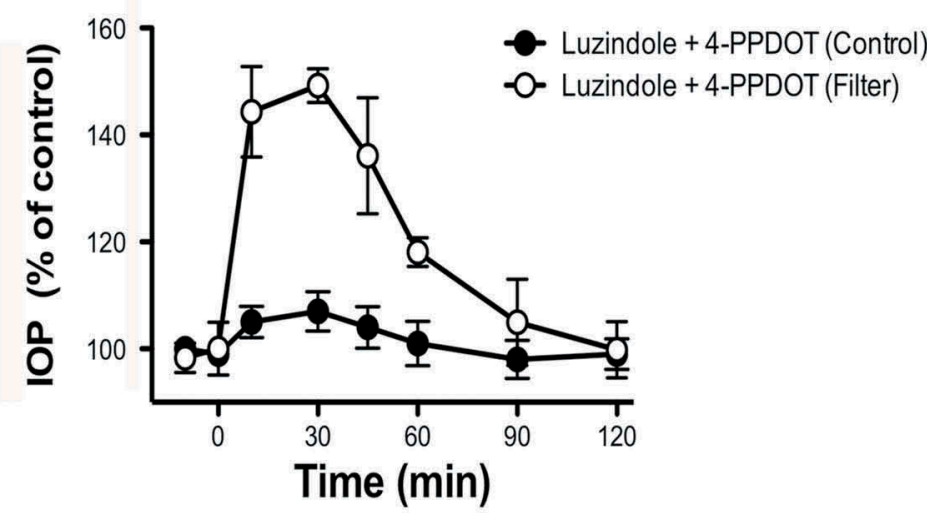

(c)

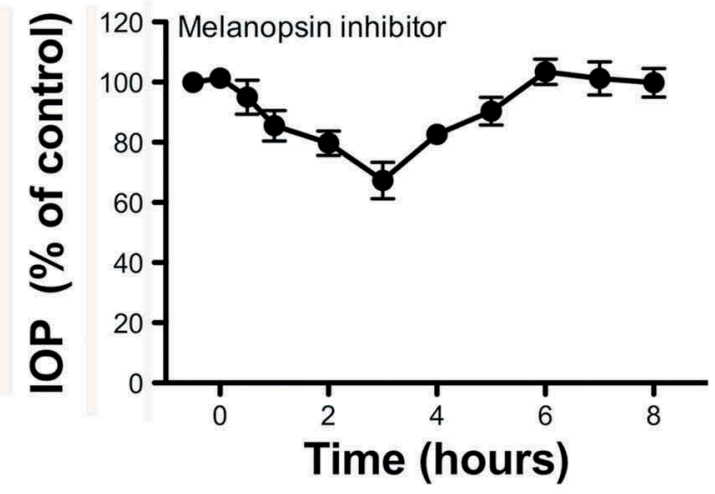

Figure 1. (A) Effect of yellow filter on rabbit intraocular pressure. Time course of yellow filter for 4 weeks followed by the recovery time in $12 / 12 \mathrm{~h}$ light darkness. Hundred percent represents the intraocular pressure before starting the experiments (i.e., at $t 0$ ) and was equivalent to $8.70 \pm 1.30 \mathrm{~mm} H \mathrm{Hg}$. Values represent the mean \pm s.e.m ${ }^{* * *} p<0.0001, n=6$ ) with respect to the control values. (B) Effect of the instillation of melatonin antagonists (luzindole +4 PPDOT) in rabbits after 3 weeks in yellow filter-covered cages compared to the control. This reduction of IOP due to the filter was completely reversed 30 min after the topical application of both the selective and nonselective melatonin receptor antagonists. (C) Line graph confirming the implication of melanopsin receptor in IOP. Hundred micrometer of melanopsin antagonist AA92593 resulted in a reduction of IOP after $2 \mathrm{~h}$ of topical instillation $\left(^{* * *} p<0.0001, n=6\right.$ ).

\section{Involvement of melanopsin on light effect and melatonin contribution}

To confirm melanopsin involvement on light effect previously described, we were able to block melanopsin by using its selective antagonist AA92593 under white light condition. Interestingly, inhibiting melanopsin under light condition resulted in a similar behavior to the one obtained by the filter. IOP dropped up to $32.7 \pm 15.0 \%\left({ }^{* * *} p<0.0001, n=6\right) 2 \mathrm{~h}$ after the application of a single dose of melanopsin antagonist compared to the control rabbits (Figure 1C).

A possible explanation for the changes observed on IOP was the possible increase in melatonin levels in the aqueous humor. As expected, melatonin levels have increased significantly from $16.33 \pm 4.50 \mathrm{ng} / \mathrm{ml}$ (before submitting rabbits to yellow filter) to $39.04 \pm 5.56 \mathrm{ng} / \mathrm{ml}$ (during the third week under the yellow filter, ${ }^{* *} p<0.0001, n=6$ ) in the aqueous humor. Control animals, those under normal white light, showed melatonin levels of $16.50 \pm 2.50 \mathrm{ng} / \mathrm{ml}$, values which did not change significantly during 8 weeks $(17.14 \pm 5.30 \mathrm{ng} /$ $\mathrm{ml}$ last week of the assay) (Figure 2).

Interestingly, the increment of melatonin levels in the aqueous humor has returned to its normal values gradually when the rabbits were moved from the yellow filter to a normal white light/darkness cycle (Figure 2). They showed $16.80 \pm 4.55 \mathrm{ng} / \mathrm{ml}$ of melatonin in the aqueous humor, this reduction is significant compared to the highest concentration found in the same animals after 3 weeks in the yellow filter $\left.{ }^{* * *} p<0.0001, n=6\right)$.

\section{Discussion}

The current work describes for the first time the effect of blocking short wavelength light over IOP. Submitting New Zealand rabbits to a yellow filter environment resulted in a decrease of IOP observed after 2 weeks. This effect was reversed by using both, the selective and nonselective melatonin receptors antagonists, 4 PPDOT and luzindole, respectively. Moreover, this indicates the role of melanopsin in regulating melatonin synthesis in the aqueous humor. From one hand, melatonin, present in the aqueous humor, was significantly higher in the rabbits under yellow filters compared to the control animals under white light. On the other hand, blocking melanopsin by means of its selective antagonist AA92593 was able to decrease IOP in rabbits living under normal light condition. 


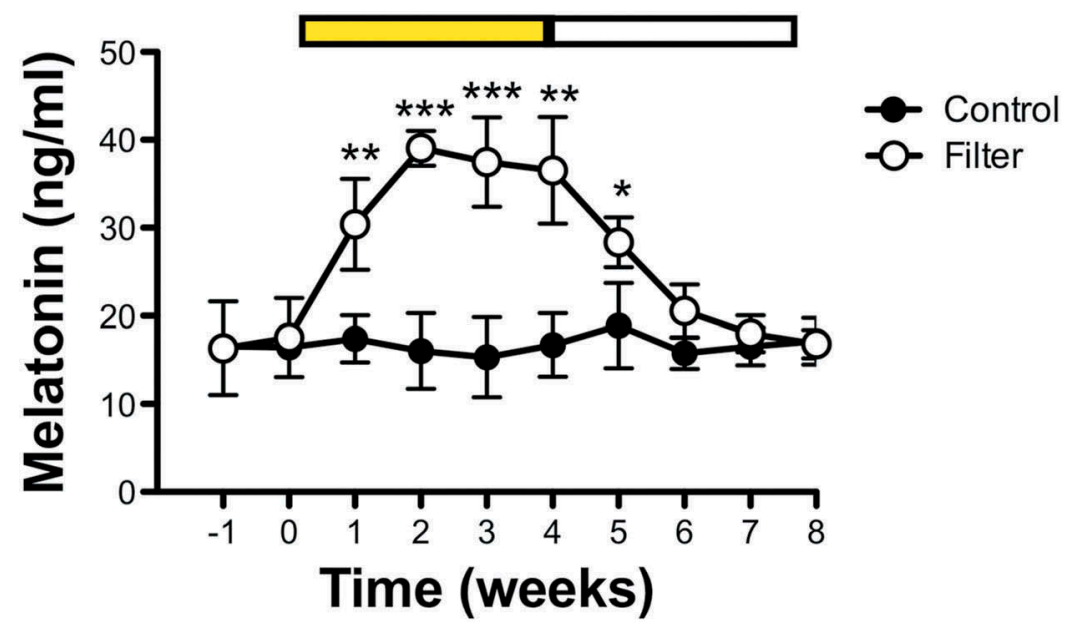

Figure 2. Presence of melatonin in the aqueous humor of New Zealand rabbits. Line graph presenting the concentrations of melatonin calculated from the chromatographic studies of controlled 12/12 light/darkness cycles compared to rabbits kept in cages enveloped with a yellow filter. Values are the mean \pm s.e.m of six independent experiments $(* * * 00.001)$.

These results are indicating a powerful effect of light modulating IOP values. Concerning the possible hypotensive effect of the yellow filters, a study by Ichikawa and colleagues was done to analyze changes in blood pressure and assess sleep duration in patients before and after they underwent cataract surgery and intraocular lens (IOL) implantation with yellowtinted lenses. Interestingly, these patients had a significant decrease of cytosolic and diastolic blood pressure 1 month after implanting the yellow-tinted IOL. ${ }^{34}$

The ability of blocking this decrease in IOP by means of antagonizing melatonin receptors is highlighting that the hypotensive effect is due to the direct binding of melatonin to its membrane receptors. These receptors are present in several structures in contact with the aqueous humor, and in this sense, studies showed that melatonin receptor activation in the nonpigmented ciliary body epithelial cells leads to a reduction of $\mathrm{Cl}^{-}$efflux and hence lowering the IOP. ${ }^{35}$ This is of great importance since it could open a possible compliment way to increase efficient melatonin in the aqueous humor as a novel way of drug delivery, by augmenting its endogenous levels as previously suggested. ${ }^{36}$

Another melatonin producing structure in the eye is the crystalline lens, where it is bathed also in the aqueous humor. ${ }^{37}$ A recent study discovered melanopsin presence in the lens, and its ability to regulate melatonin secretion from the epithelial lens cells. ${ }^{31}$ Although results in that study indicated an increment of melatonin after $8 \mathrm{~h}$ of incubation in darkness that effect was blocked by the melanopsin antagonist. In the present work, the blockade of melanopsin by means of the antagonist AA92593 produced an increment in melatonin levels resulting in a drop of IOP. This effect could be explained by the activation of the key enzyme of melatonin synthesis, AANAT, since it can trigger melatonin production in a very quick manner. ${ }^{38}$ Very recently, it has been possible to demonstrate that a yellow filter can modify the release of the nucleotide ATP from rabbit lenses. Interestingly, either with the whole animal or with cultured lenses, the blockade of melanopsin significantly reduced the release of ATP. ${ }^{33}$ This is indicating that light, activating the photopigment melanopsin, can induce the release of this nucleotide. On the contrary, and as described in the present work, light inhibits the synthesis of melatonin. Although the functions of melatonin and ATP in the eye are different, ${ }^{39}$ the possibility of modifying the presence of these substances by using a filter is something relevant. It is possible by using filters to increase the presence of melatonin and to decrease the release of $\mathrm{ATP},{ }^{33}$ therefore acting pharmacologically without using drugs but by using the light as an agonist or antagonist. ${ }^{40}$

In summary, melanopsin photo pigment plays an indirect, still important role on IOP modulation through the regulation of melatonin production in the aqueous humor. The use of yellow filters blocking blue light could be a novel approach to reduce IOP and prevent the progression of glaucoma.

\section{Acknowledgments}

Hanan A. Alkozi is a fellowship holder of the Saudi Arabia government.

\section{Disclosure statement}

No potential conflict of interest was reported by the authors.

\section{Funding}

This work was supported by grants from Ministerio de Economía y Competitividad: [Grant Number SAF2013-44416-R] and [Grant Number SAF2016-77084R], and Ministerio de Sanidad RETICS: [Grant Number RD12/0034/0003] and [Grant Number RD16/0008/0017].

\section{References}

1. Lerner $A B$, Case JD, Takahashi Y. Isolation of melatonin and 5-methoxyindole-3-acetic acid from bovine pineal glands. J Biol Chem. 1960;235:1992-97.

2. Bubenik GA, Brown GM, Uhlir I, Grota LJ. Immunohistological localization of $\mathrm{N}$-acetylindolealkylamines in pineal gland, retina and cerebellum. Brain Res. 1974;81:233-42. 
3. Aimoto T, Rohde BH, Chiou GC, Lauber JK. N-acetyltransferase activity and melatonin level in the eyes of glaucomatous chickens. J Ocul Pharmacol. 1985;1:149-60.

4. Quay WB. Increases in volume, fluid content, and lens weight of eyes following systemic administration of melatonin. J Pineal Res. $1984 ; 1: 3-13$

5. Abe M, Itoh MT, Miyata M, Shimizu K, Sumi Y. Circadian rhythm of serotonin $\mathrm{N}$-acetyltransferase activity in rat lens. Exp Eye Res. 2000;70(6):805-08. doi:10.1006/exer.2000.0845.

6. Mhatre MC, van Jaarsveld AS, Reiter RJ. Melatonin in the lacrimal gland: first demonstration and experimental manipulation. Biochem Biophys Res Commun. 1988;153:1186-92.

7. Crooke A, Guzman-Aranguez A, Mediero A, Alarma-Estrany P, Carracedo G, Pelaez T, Peral A, Pintor J. Effect of melatonin and analogues on corneal wound healing: involvement of Mt2 melatonin receptor. Curr Eye Res. 2015;40(1):56-65. doi:10.3109/ 02713683.2014.914540.

8. Bardak Y, Ozerturk Y, Ozguner F, Durmus M, Delibas N. Effect of melatonin against oxidative stress in ultraviolet-B exposed rat lens. Curr Eye Res. 2000;20:225-30.

9. Ali $\mathrm{T}$, Badshah $\mathrm{H}$, Kim $\mathrm{TH}$, Kim MO. Melatonin attenuates D-galactose-induced memory impairment, neuroinflammation and neurodegeneration via RAGE/NF-K B/JNK signaling pathway in aging mouse model. J Pineal Res. 2015;58(1):71-85. doi:10.1111/ jpi.12194.

10. Blasiak J, Reiter RJ, Kaarniranta K. Melatonin in retinal physiology and pathology: the case of age-related macular degeneration. Oxid Med Cell Longev. 2016;2016:6819736. doi:10.1155/2016/6819736.

11. Crooke A, Colligris B, Pintor J. Update in glaucoma medicinal chemistry: emerging evidence for the importance of melatonin analogues. Curr Med Chem. 2012;19:3508-22.

12. Crooke A, Huete-Toral F, Martinez-Aguila A, Martin-Gil A, Pintor J. Melatonin and its analog 5-methoxycarbonylamino$\mathrm{N}$-acetyltryptamine potentiate adrenergic receptor-mediated ocular hypotensive effects in rabbits: significance for combination therapy in glaucoma. J Pharmacol Exp Ther. 2013;346 (1):138-45. doi:10.1124/jpet.112.202036.

13. Casson RJ, Chidlow G, Wood JP, Crowston JG, Goldberg I. Definition of glaucoma: clinical and experimental concepts. Clin Exp Ophthalmol. 2012;40(4):341-49. doi:10.1111/j.14429071.2012.02773.x.

14. Quigley HA. Glaucoma. Lancet. 2011;377(9774):1367-77. doi:10.1016/S0140-6736(10)61423-7.

15. Topouzis F, Harris A, Wilson MR, Koskosas A, Founti P, Yu F, Anastasopoulos E, Pappas T, Coleman AL. Increased likelihood of glaucoma at the same screening intraocular pressure in subjects with pseudoexfoliation: the Thessaloniki eye study. Am J Ophthalmol. 2009;148(4):606-13 e1. doi:10.1016/j.ajo.2009.03.024.

16. Provencio I, Rodriguez IR, Jiang G, Hayes WP, Moreira EF, Rollag MD. A novel human opsin in the inner retina. J Neurosci. 2000;20(2):600-05. doi:10.1523/JNEUROSCI.20-0200600.2000 .

17. Panda S, Provencio I, Tu DC, Pires SS, Rollag MD, Castrucci AM, Pletcher MT, Sato TK, Wiltshire T, Andahazy M, et al. Melanopsin is required for non-image-forming photic responses in blind mice. Science. 2003;301(5632):525-27. doi:10.1126/science.1086179.

18. Provencio I. The hidden organ in your eyes. Sci Am. 2011;304:54-59.

19. Rollag MD, Berson DM, Provencio I. Melanopsin, ganglion-cell photoreceptors, and mammalian photoentrainment. J Biol Rhythms. 2003;18(3):227-34. doi:10.1177/0748730403018003005.

20. The medical and biological effects of light. Conference on medical and biological effects of light. New York City, October 31-November 2, 1984. Ann N Y Acad Sci. 1985;453:1-408.

21. Erren TC, Reiter RJ, Piekarski C. Light, timing of biological rhythms, and chronodisruption in man. Naturwissenschaften. 2003;90(11):485-94. doi:10.1007/s00114-003-0468-6.
22. Weitzman ED, Czeisler CA, Zimmerman JC, Moore-Ede MC. Biological rhythms in man: relationship of sleep-wake, cortisol, growth hormone, and temperature during temporal isolation. Adv Biochem Psychopharmacol. 1981;28:475-99.

23. Sack RL, Auckley D, Auger RR, Carskadon MA, Wright KP Jr., Vitiello MV, Zhdanova IV. Circadian rhythm sleep disorders: part I, basic principles, shift work and jet lag disorders. An American academy of sleep medicine review. Sleep. 2007;30:1460-83.

24. Lucas RJ, Peirson SN, Berson DM, Brown TM, Cooper HM, Czeisler CA, Figueiro MG, Gamlin PD, Lockley SW, O'Hagan JB, et al. Measuring and using light in the melanopsin age. Trends Neurosci. 2014;37(1):1-9. doi:10.1016/j.tins.2013.10.004.

25. Lam RW, Zis AP, Grewal A, Delgado PL, Charney DS, Krystal JH. Effects of rapid tryptophan depletion in patients with seasonal affective disorder in remission after light therapy. Arch Gen Psychiatry. 1996;53:41-44.

26. Glickman G, Byrne B, Pineda C, Hauck WW, Brainard GC. Light therapy for seasonal affective disorder with blue narrow-band light-emitting diodes (LEDs). Biol Psychiatry. 2006;59(6):502-07. doi:10.1016/j.biopsych.2005.07.006.

27. Leppamaki S. Light and mood therapy. Duodecim. 2005;121:2600-05.

28. Terman M, Terman JS. Light therapy for seasonal and nonseasonal depression: efficacy, protocol, safety, and side effects. CNS Spectr. 2005;10(8):647-63. quiz 72.

29. Wenzel A, Grimm C, Samardzija M, Reme CE. Molecular mechanisms of light-induced photoreceptor apoptosis and neuroprotection for retinal degeneration. Prog Retin Eye Res. 2005;24 (2):275-306. doi:10.1016/j.preteyeres.2004.08.002.

30. Organisciak DT, Vaughan DK. Retinal light damage: mechanisms and protection. Prog Retin Eye Res. 2010;29(2):113-34. doi:10.1016/j.preteyeres.2009.11.004.

31. Alkozi HA, Wang X, Perez de Lara MJ, Pintor J. Presence of melanopsin in human crystalline lens epithelial cells and its role in melatonin synthesis. Exp Eye Res. 2016;154:168-176.

32. Alkozi HA, Pintor J. TRPV4 activation triggers the release of melatonin from human non-pigmented ciliary epithelial cells. Exp Eye Res. 2015;136:34-37. doi:10.1016/j.exer.2015.04.019.

33. Pintor J. Light-induced ATP release from the lens. Purinergic Signal. 2018. doi:10.1007/s11302-018-9626-3.

34. Ichikawa K; investigators Cs. Changes in blood pressure and sleep duration in patients with blue light-blocking/yellow-tinted intraocular lens (CHUKYO study). Hypertens Res. 2014;37(7):659-64. doi:10.1038/hr.2014.50.

35. Huete-Toral F, Crooke A, Martinez-Aguila A, Pintor J. Melatonin receptors trigger cAMP production and inhibit chloride movements in nonpigmented ciliary epithelial cells. J Pharmacol Exp Ther. 2015;352(1):119-28. doi:10.1124/jpet.114.218263.

36. Pintor H. Improving melatonin delivery within the eye. J Bioequiv Availab. 2017;9:516-17.

37. Abe M, Itoh MT, Miyata M, Ishikawa S, Sumi Y. Detection of melatonin, its precursors and related enzyme activities in rabbit lens. Exp Eye Res. 1999;68(2):255-62. doi:10.1006/ exer.1998.0601.

38. Alkozi HA, Perez de Lara MJ, Pintor J. Melatonin synthesis in the human ciliary body triggered by TRPV4 activation: involvement of AANAT phosphorylation. Exp Eye Res. 2017;162:1-8. doi:10.1016/j.exer.2017.06.018.

39. Sanderson J, Dartt DA, Trinkaus-Randall V, Pintor J, Civan MM, Delamere NA, Fletcher EL, Salt TE, Grosche A, Mitchell CH. Purines in the eye: recent evidence for the physiological and pathological role of purines in the RPE, retinal neurons, astrocytes, Muller cells, lens, trabecular meshwork, cornea and lacrimal gland. Exp Eye Res. 2014;127:270-79. doi:10.1016/j. exer.2014.08.009.

40. Pintor J. Pharmacology without drugs. J Optom. 2018;11 (4):201-02. doi:10.1016/j.optom.2018.06.002. 